Article

\title{
Automation of the Road Gate Operations Process at the Container Terminal-A Case Study of DCT Gdańsk SA
}

\author{
Karol Moszyk ${ }^{1,2, *}$, Mariusz Deja ${ }^{3, *}$ ad and Michal Dobrzynski $^{3}$ (D) \\ 1 Doctoral Studies-Implementation Doctorate, Faculty of Mechanical Engineering and Ship Technology, \\ Gdańsk University of Technology, G. Narutowicza Str. 11/12, 80-233 Gdańsk, Poland \\ 2 Operations Department, PSA Group, DCT Gdańsk SA, Deepwater Container Terminal Gdańsk, \\ Kontenerowa Str. 7, 80-601 Gdańsk, Poland \\ 3 Department of Manufacturing and Production Engineering, Faculty of Mechanical Engineering and Ship \\ Technology, Gdańsk University of Technology, G. Narutowicza Str. 11/12, 80-233 Gdańsk, Poland; \\ michal.dobrzynski@pg.edu.pl \\ * Correspondence: karol.moszyk@pg.edu.pl (K.M.); mariusz.deja@pg.edu.pl (M.D.); \\ Tel.: +48-607-760-235 (K.M.)
}

Citation: Moszyk, K.; Deja, M.; Dobrzynski, M. Automation of the Road Gate Operations Process at the Container Terminal-A Case Study of DCT Gdańsk SA. Sustainability 2021, 13, 6291. https://doi.org/10.3390/ su13116291

Academic Editors: Jozef Gašparík and Davor Dujak

Received: 9 April 2021

Accepted: 27 May 2021

Published: 2 June 2021

Publisher's Note: MDPI stays neutral with regard to jurisdictional claims in published maps and institutional affiliations.

Copyright: (c) 2021 by the authors. Licensee MDPI, Basel, Switzerland. This article is an open access article distributed under the terms and conditions of the Creative Commons Attribution (CC BY) license (https:// creativecommons.org/licenses/by/ $4.0 /)$.

\begin{abstract}
The future increased terminal capacity will result in more container movement through the road complex and rail siding, which are one of the most critical areas (potential bottlenecks) in the container terminal. Truck turnaround time is one of the major factors that customers take into account while deciding how many container volumes they will handle through the container terminal. To enable to optimize increased traffic with future container terminal development, as well as increase gates throughput, and as a consequence, encourage more volume and increase customer satisfaction, Deepwater Container Terminal Gdańsk SA plans to reorganize and automatize the gate operation process. Gate automation includes supply, installation, commissioning, implementation, and maintenance of software and hardware that would allow automatizing the handling of trucks at container terminal gates by using OCR (optical camera recognition) technology, LPR (license plate recognition) systems and self-service kiosk for truck drivers.
\end{abstract}

Keywords: container terminal; optical camera recognition; OCR; gate automation; process automation; container handling

\section{Introduction}

Ships, as a transportation unit, have rapidly increased in size. The main reason is the mass transportation, which has lowered the cost per TEU (twenty equivalent unit), allowing for an economy of scale. An increase of cargo capacity on the single vessel ocean road improves reliability and reduces shipping cost. Such a trend raises a question regarding whether existing ports and terminals are able to cope in a safe and efficient manner with ships or not [1].

Container terminals are and will follow the Ocean Alliances routes to increase their terminal assets. Container handling equipment such as ships to shore cranes will be taller and wider, the number of yard cranes will grow significantly in order to follow the assumed and agreed terminal performance indicators.

World container volumes continue to grow with the introduction of grater containerships into major trade routes. The port industry is under pressure to deal with the ever-increasing freight volume. Containerships of 24,000 TEUs plus are common for the terminals which serve as the main hubs. Larger ships wait longer than smaller units due to the difficulty in allocating the proper seat on the berth [2]. In addition, the available stacking area and the number of handling equipment can be limited, extending the time for loading/unloading operations [3]. The terminal operation activities related to its landside, such as outbound containers transportation using internal moving vehicles (IMVs) and 
their stowage into the assigned storage yards was studied in [4]. The dynamic data mining of ship container route loading under the international logistics environment was realized in [5]. In addition to the above-mentioned problems, gate congestion at a marine container terminal is considered a major issue facing truckers who come to the terminal for container pickup and delivery [1]. As a consequence of a large volume of cargo entering or leaving a port via road, congestions or emissions often become a social problem even in the large area adjacent to the terminal [6].

Terminals are facing multiple types and numbers of daily, weekly, and monthly peaks. Ships are approaching their premises with an unprecedented amount of container volumes which needs to be discharged and loaded to the next mode of transport-ship, truck, train or barge. Road and rail gates are exposed to the direct impact of cargo flows, and only the best prepared, equipped and managed gate complexes will be able to cope with that.

Marine container terminals are dependent on efficient gate operations which are crucial. Their impact is not isolated to the efficiency of the operations within the terminal but also extends to the traffic on nearby roads and access tracks. The surrounding roadway and rail network can be spilled by inefficient gate operations, causing serious safety and congestion problems, and degrading the reliability and performance of carriers, shippers, and terminal operators. Implementing operational strategies to reduce the effect of the terminals truck and train related traffic on the surrounding roadway and rail track network becomes more important and more viable than physical capacity expansions since container terminals tend to be located in or near major cities [7].

Road and rail gates are the eyes of the terminal, whenever something is wrong with them, everybody around knows about it. Efficiency of gate complex and its throughput is one of the main factors which determine how many container volumes will be handled. Uninterrupted, constant and safe flow of loads is the reason and consequence which brings more volume and increases customer satisfaction.

The implementation of different gate operation strategies can be certain fundamental options that may relieve these effects. Advanced technologies applied to gates and terminals are among the gate operation strategies being considered to relieve the impacts of congestion and delay [8].

Container terminal works internally or with third party solution providers with the different approaches to gate complex efficiency. Many internal and external ideas, projects, and strategies can be applied to support the increase of container throughput and truck/train turnaround time.

The purpose of this paper is to examine the efforts of introducing a gate optimization process and understand the success and failures of such project introduction. This paper also presents existing attempts at reducing congestions in the queues of trucks at terminal gates, and improving terminal operations and traffic conditions in the vicinity of the terminals and the technologies available that support the implementation of this type of strategies as presented in [9].

\section{Assessment of the Current Situation at DCT Gdańsk SA}

\subsection{Problem Overview}

In the last twenty years, international trade has greatly increased, in particular between Asian and Europe, marine container terminals and especially for movements involving intermodal containers. Marine container terminal represents major nodes of transportation networks where most of the world's goods are transferred and freight commodities leave and arrive via trucks, trains, and vessels. Demand for all modes of transportation carrying freight has increased. The transportation systems of metropolitan areas have been impacted by the increase of trade, especially around the major generators (ports, airports, intermodal terminals, and industrial areas) causing congestion, delays, and air and noise pollution (Bureau of Transportation Statistics 2006) [10].

Marine container terminals are located not in the far reach of the busiest cities and regions were their location supports those areas and gives the opportunity to grow. The 
importance of having a cargo reloading point in close proximity is invaluable. The point of which will generate and accelerate the whole transportation ecosystem and which will allows us to increase cargo flows from adjacent regions or countries.

Container terminals are typically defined as restricted areas, because of homeland security and customs duties. All visitors and/or equipment delivered such as containers, tracks, cars and people must be identified and recorded when they are entering or leaving a terminal. Every terminal sets up gate complexes to play a role of checkpoints to deal with these entities. Once any visitor arrives at a gate complex defined as the entry point, it has to be identified. If there is no problem, its data will be recorded, and it will be allowed to pass through the gate [11].

The fact that truckers are choosing specific hours of day, where they enter and exit the terminal to deliver or pick-up a container is one of the major challenges at marine container terminals. Consequently, trucks are causing peak hours, resulting in high demand over certain periods $[12,13]$.

Peak hours for road and rail traffic can be truly problematic and the terminal can face several challenges. Therefore, terminal operators apply multiple strategies-operational and commercial— to avoid and/or flatten the top of the peak hours, which by themselves are unavoidable.

Even if peak hours do not occur, container terminal gates are the source of congestion due to in-gate processing delays. A typical in-gate process includes the manual verification of truck driver and container and equipment inspection. These delays vary according to the transaction type and the degree of manual inspection experience at the terminal gate. A typical delay at a terminal entrance gate is four to five minutes [14].

Another challenge which can cause huge congestion for upcoming to and leaving from terminal trains is the port infrastructure to terminal gates, single rail track, and/or inefficient shunting station. As a result of not allowing the train to leave the terminal and not have more space to accommodate the next one, this can lead to a backlog in rail operations and potential terminal rail siding stoppages.

Container terminals are not alone in gaining the port efficiency and increasing the container throughput. Direct support of marine ports is crucial in that manner. Building the supporting infrastructure such as two lane roadways and the second rail track is an indisputably important aspect of every terminal entry.

Ports and terminals need to cope with internal and external congestion challenges. Inside the terminal, the mixed traffic of internal prime movers and external trucks cannot be easily transferred outside the boundaries without any notice. Terminals cannot forget about the surrounding transportation network and potential bottlenecks which congestion can generate. They are all time monitored by their users-truckers, the train operator-who, whenever any challenge occurs, inform all possible channels including the media.

The issues with increasing port congestion may also extend to the container terminal area. Inside their yards and container blocks, high demand external peaks coupled with capacity and equipment availability problems can influence negatively on the reliability and performance of the terminal. In addition to these challenges, environmental effects stemming from idling trucks have further emerged as a serious problem, as the emissions have negative impact on the whole communities living in the surroundings [15-18].

In this paper, we will describe the implementation of various operational road gate strategies that reduce congestion effects. These strategies include different automation technologies that encourage the implementation of operational strategies.

\subsection{Operation Strategies at Container Terminal to Relieve Truck Traffic Congestion}

Container terminals are an open system of container flow with two external entrance points: the waterside where containers are discharge/loaded from/to vessels and the landside where containers arrive/leave the terminal via trucks or trains. Within the terminal area, we can differentiate four areas: the quay where vessels are berthed for operations, the storage yard where containers are placed waiting to be exported, imported 
or transshipped, the container freight station where containers are serviced and the terminal gate which connects the container terminal with the hinterland. The terminal area of Deepwater Container Terminal Gdańsk SA (DCT Gdańsk SA) is presented in Figure 1.

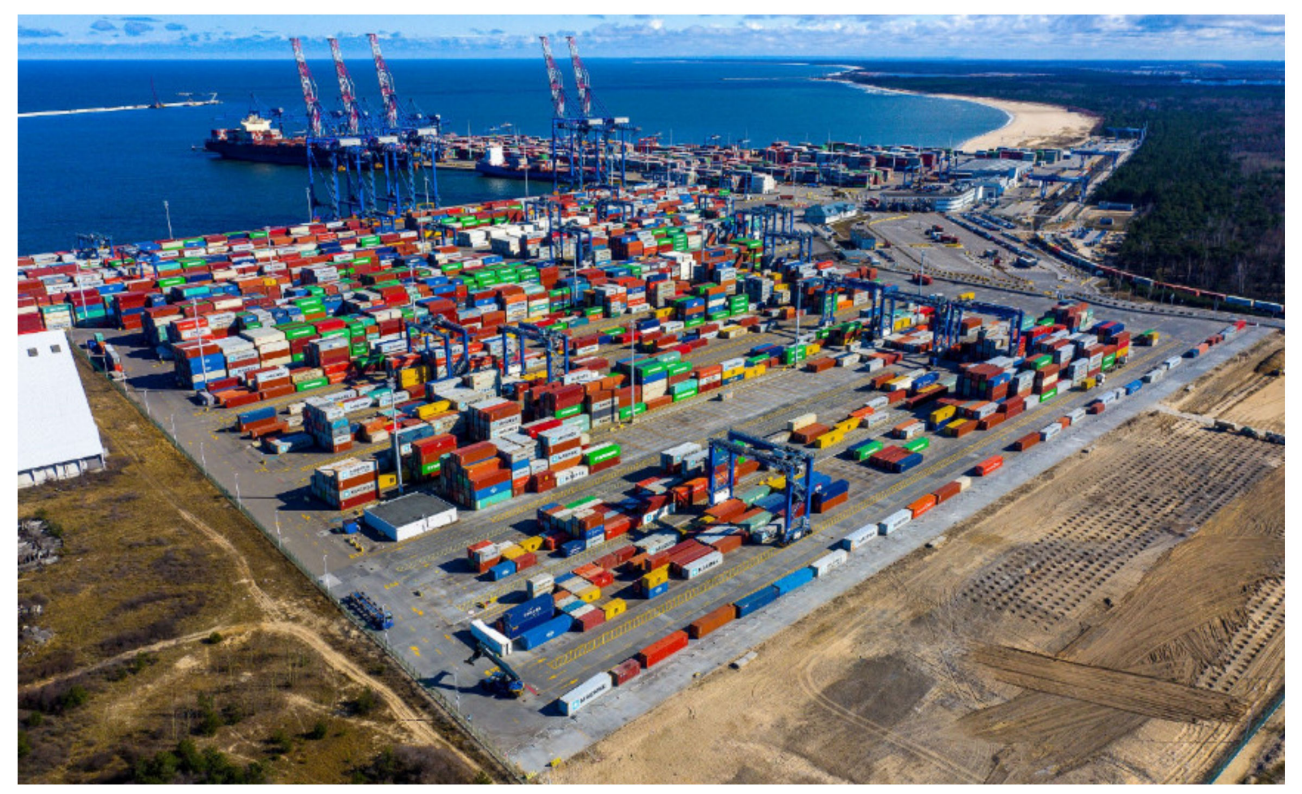

Figure 1. Terminal area-DCT Gdańsk SA.

Operations in a container terminal can be divided into three categories: waterside operations, landside operations, and yard operations. Waterside operations consist of the vessels maneuvering and berthing operations at the quay. When the vessel is safely moored and stevedores prepared containers for operations, the process of unloading and loading can proceed. The waterside operations interact with the yard operations via the internal transport equipment-prime movers-used to transport containers from/to the vessel and to/from the storage yard.

The seaside operations include dozens of internal trucks which are feeding the ship to shore cranes. Internal trucks are collecting containers in the yard and delivering them to the quay. Seaside operations in DCT Gdańsk SA are presented in Figure 2. On the single quay are to be located between up to seven internal truck lines-depends on the ship to shore dimensions-DCT Gdańsk Terminal one has six lines and Terminal 2 has seven lines. Every ship on shore is fed by a number of internal trucks-depending on the terminal operational condition-up to 10-12 internal trucks per single crane. If we count that, on the single vessel operates up to 10 ships on the shore crane-on that vessel we will have up to 120 internal trucks movements.

The yard operations deal with containers between the landside and the waterside. It includes container handling operations from/to the vessel and from/to the trucks/rail, and the storage operations in the storage container blocks. The landside operations manage the activities of receiving and delivering inbound and outbound containers to and from the storage container blocks.

All container terminal systems can be seen independently, nevertheless the interactions between them are unavoidable and play a crucial role in the efficient management and operation of a container terminal. A schematic description of container terminal operations and interactions between the different systems is presented in Figure 3. 


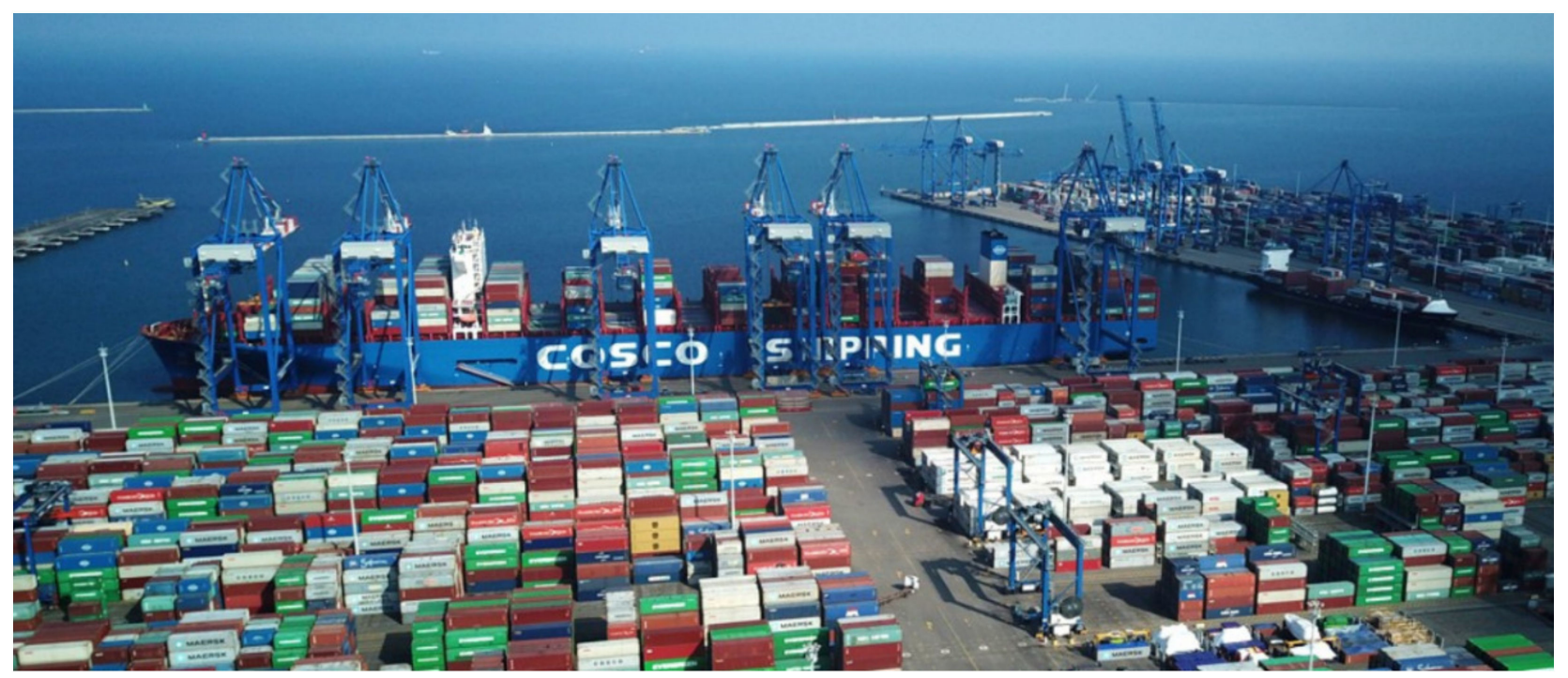

Figure 2. Seaside operations-DCT Gdańsk SA.

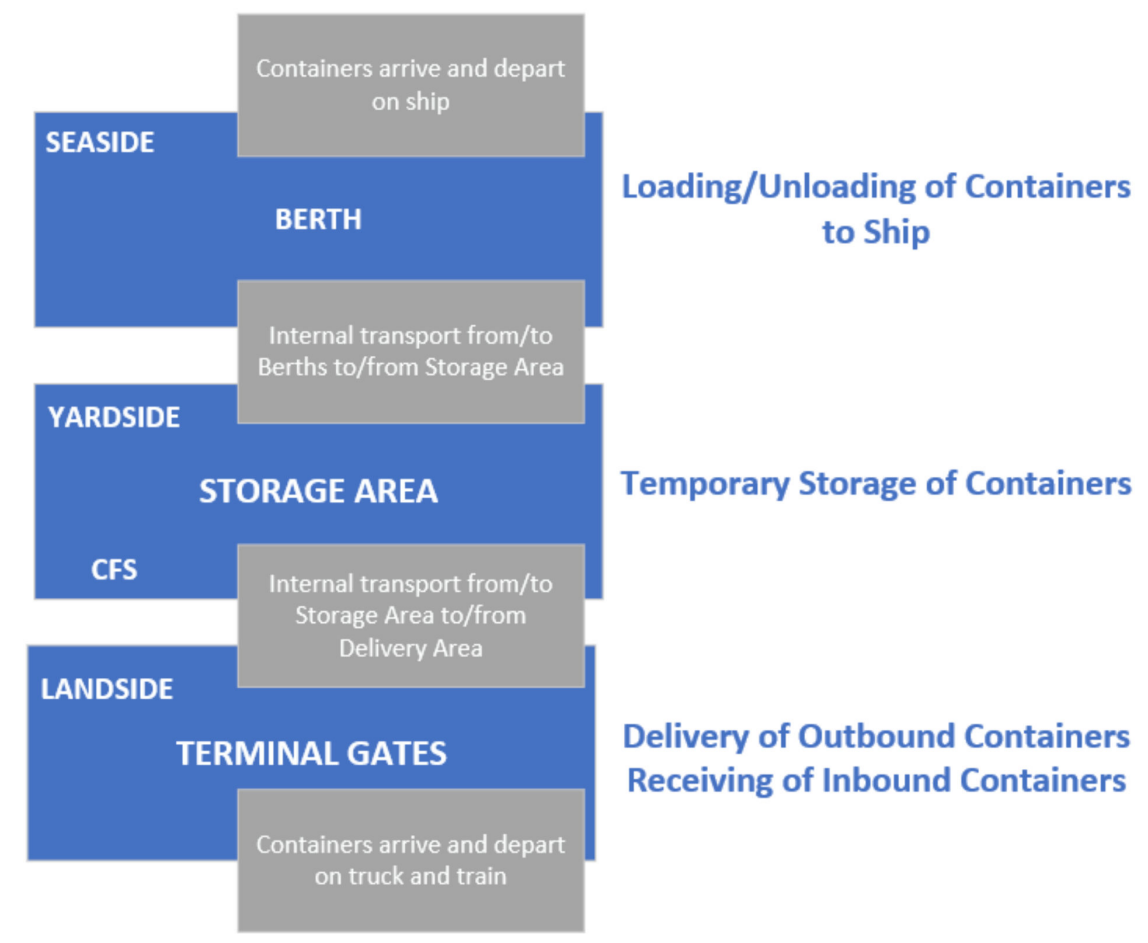

Figure 3. Schematic representation of container terminal activities and operations-based on Reference [7].

DCT Gdańsk SA terminal operation results from the 2020 year can be seen in Table 1. During a single year we can observe cargo flows fluctuations and seasonality. The container terminal needs to be prepared for different scenarios and volume changes during the year. All of them are directly influencing the yard situation and condition as well as the number of trucks involved in the continuous cargo flow. On the seaside operations, all containers are discharged and loaded by internal trucks, containers rehandled in the yard, road operations are delivered/received by external trucks, and rail plus container freight station (CFS) operations are serviced by internal trucks. 
Table 1. Terminal operation results from 2020 year-DCT Gdansk.

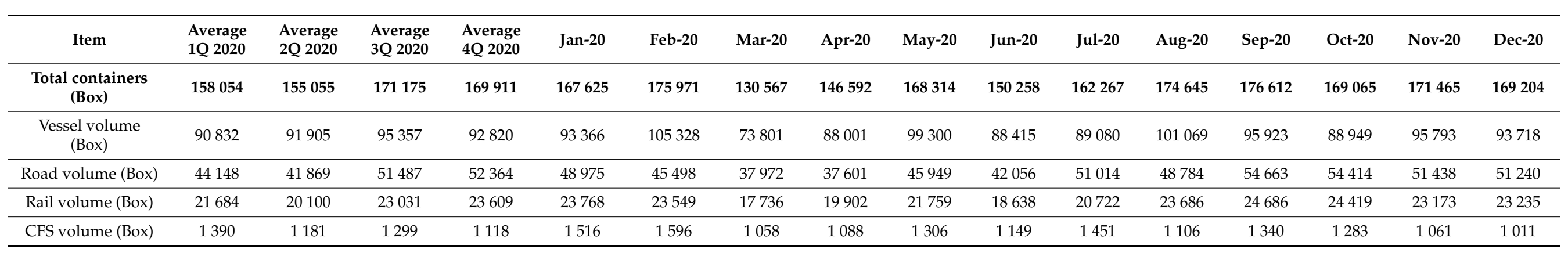


What is important to be noticed is the fact that on average DCT Gdańsk handles around 50,000 containers through its road gate complex. DCT road gates are open 24/7 besides Saturdays after 14:00, Sundays until 14:00, and Holidays. We can state that DCT on a daily basis handles roughly 2000 boxes.

\section{Methods and Methodology}

The research methodology used in the case study included the following stages:

- Evaluation of an environmental impact-due to the fact that container terminals are in the close location of the cities and their centers. The observation showed that a high number of external trucks (thousands per day) and their waiting for entry terminal premises in the nearby parkings, roads, depots or logistics centers could directly impact the city ecosystem by raising pollution.

- Identification of bottlenecks-before entering the port terminal area, in many cases external trucks need to follow one direction roads with bridges and viaducts, which during the constant port development could have additional narrowing. There have been cases reported when one single traffic accident on the bridge, in the tunnel or by the rail crossing has blocked road operations for hours-after resumption of the traffic, the container terminal faces a huge peak of container volumes which needs to be served.

- Definition of assumptions:

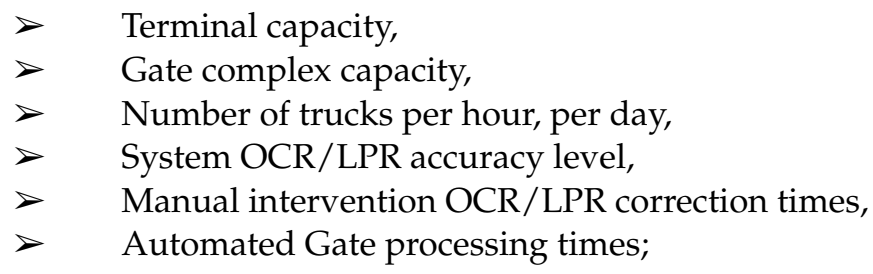

The assumptions taken into account in the analyzes are presented in Section 5.1.

- Evaluation of automated gate layout - the number of IN and OUT OCR portals, gates and self-service kiosks which need to be developed and utilized on a daily basis. Gate layout in every container terminal is an important element of safe and efficient road operations. The individual factors taken into consideration when building Automated Gate are shown in Section 5.1.

- Simulation results of the automated gate-investigation of the external truck number awaiting in the que before entering and leaving the container terminal. External truck queues before entering and leaving the terminal premises are the most important element to be determined before the final execution of the proposed automated gate layout. Simulation results are presented in Section 5.2.

- Verification of the current status of processing times and accuracy levels. Confirmation of the agreed service levels and hit rate thresholds gives confidence in automated gate implementation. The results presented in Section 5.3 clearly show that the current accuracy rate is higher than assumed.

- Confirmation of the final automated gate layout. The final layout created based on the developed methodology is shown in Section 5.4.

\section{Automated Gate Strategies}

Growth of cargo volumes and truck traffic in the container terminal has influenced terminal operators to use new advanced automation technologies for container and truck and trailer management. Utilization of these systems increases gate efficiency, throughput and truck turnaround time through the entire terminal. Every individual terminal is different and must decide which technologies to implement within their premises to maximize operational efficiency and security.

The gate automation main goals are as follows: 
- Increase the safety of employees—reduce of gate checkers from human-machine interactions;

- Increase the safety of truck drivers-trainings, safety test, and automatic verification of drivers on black-list;

- Increase the capacity and assure the possibility of handling more than 200 trucks per hour on the road gates;

- Increase data accuracy;

- Increase data availability-less than $3 \mathrm{~s}$ after passing through, data from OCR gate is correctly available for the TOS to work with;

- Increase post-processing proof-issues, errors, and information can be traced back to the root, supported with visual proof. This has a serious impact on the resources necessary for damage claims management and tracking and tracing;

- Add value to customers and users-visit retrieval applications allow customers to directly track images of containers booked under their user profile;

- Decrease the number of employees who are working in the risky gate complex environment;

- The uniform representation of data allows easy KPI measurements, reporting and spotting areas for improvement (potential of continuous improving and changing process and applications).

Finally, for a terminal operator, it also means that the automation within an area enables to free valuable resources and deploy them in areas that are less appropriate for automation. This means that gate automation is a mature technology that bears little to no risk of failure. The employees can be trained to execute more value adding tasks for the yard.

Automated identification and data collection (AIDC) technologies such as optical camera recognition (OCR), barcode, GPS (global positioning system), and RFID (radio frequency identification) are available for tracking assets and automating processes within port and terminal environments [19].

\subsection{OCR Technology}

OCR is used worldwide for the recognition and identification of equipment markings (i.e., the container number, truck and trailer license plates) and to record the condition of the equipment itself. The main benefit of OCR technology is the fact that it provides a reliable method of identification, without any need to apply a dedicated tag or device to the asset.

OCR technology has so far been introduced to deliver benefits including labor productivity, safety and security. OCR is unique in that it automates 'hands free' identification and locating of assets, but also the recording of an object's visual condition at that time. If the automatic recognition of the object fails-which occurs in 3-5\% of all attempts due to damaged numbering - a visual record (digital image) of the equipment ID is available for exception management and data correction [11,12].

OCR is based on images, the better the image, the better the OCR result will be. In addition to the OCR processing, the quality of images is as well important for efficient exception handling: the best exception help desk is worthless without the availability of good, high-resolution and 'readable' images. Acquiring the images and OCR data on the road gate is not a simple task, the typical camera and OCR process when a truck is passing the portal is presented in Figure 4.

Making pictures of moving objects like containers being transported by trucks is not as simple as it looks; there is only a short, single moment to make the perfect picture. In that timeslot, sometimes no more than a few milliseconds, all camera parameters should be in the right position, otherwise the picture is worthless. Often the picture will be too bright or too dark as camera electronics cannot follow fast changing light conditions. 

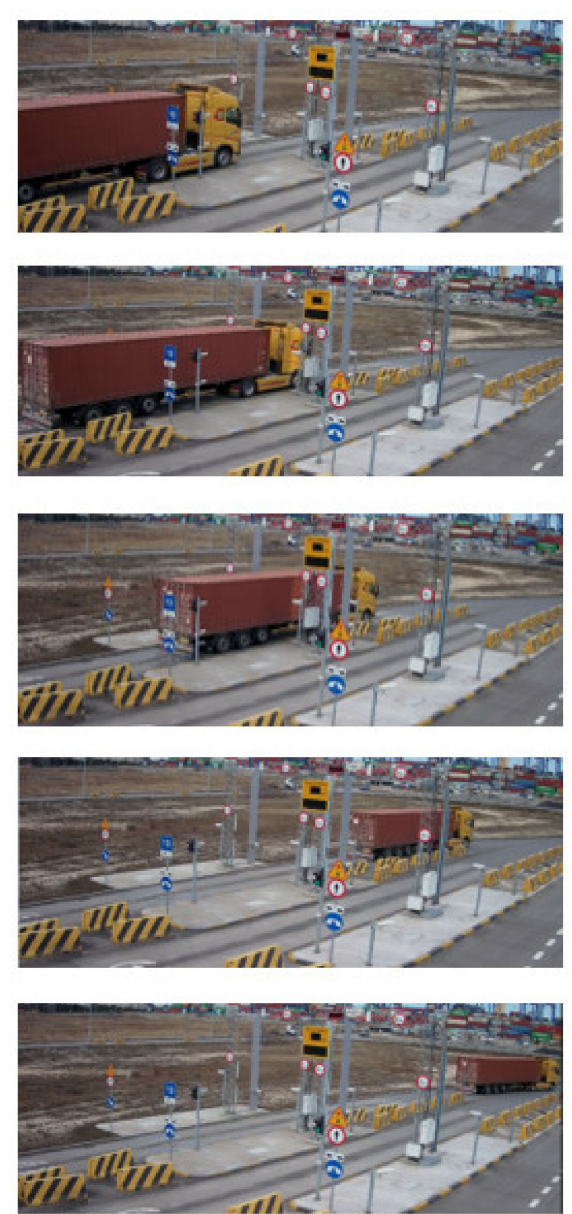

\section{Start scanning}

Trigger system detects truck and instructs cameras to capture images and turn lights on

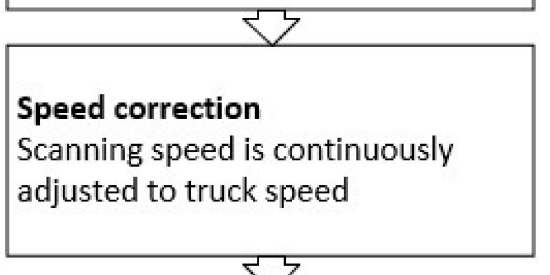

\begin{tabular}{l} 
Segmenting \\
Detection of truck/container \\
boundaries, used for segmenting \\
the images \\
$\begin{array}{l}\text { Stop scanning } \\
\text { Detection of truck/container end is } \\
\text { signal to stop scanning and to turn } \\
\text { the lights off }\end{array}$ \\
\hline
\end{tabular}

\section{Data transfer}

Cameras send JPEG-images and OCR-results to server, just a few seconds after stopping. The system is ready for the next truck

Figure 4. Acquiring the images and OCR data on the automated road gate.

For OCR processing, special industrial cameras are used. This camera market is a fast competitive market. Every year new camera models become available, with new cable interfaces, new API's, new lenses, etc.

Line-scan camera technology, as described in Figure 5, is a special technique that 'scans' the surface of the containers instead of making 2D pictures, which are 'stitched' together in post-processing. Line-scan systems guarantee the highest resolution and quality pictures.
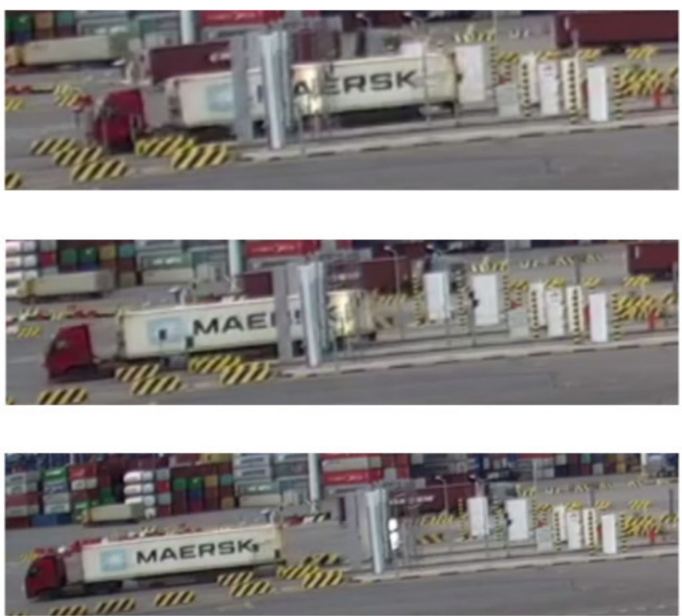

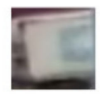

Picture in side camera

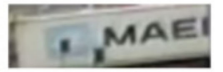

Picture in side camera

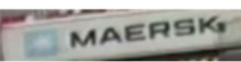

Picture in side camera

Line scan process. Picture is build-app line by line

Figure 5. Line scan technology. 


\subsection{RFID Technology}

RFID (radio frequency identification) technology is another type of automated identification and data collection (AIDC) technology. In our day to day lives, RFID can be found everywhere-in our work as access cards, in private live from passports to toll tags. The concept of RFID technology is not complicated, every object to be tracked by the reader is identified with a "tag" or transponder. The RFID system, as explained in Figure 6, consists of three basic modules: tags, readers, and data processors.

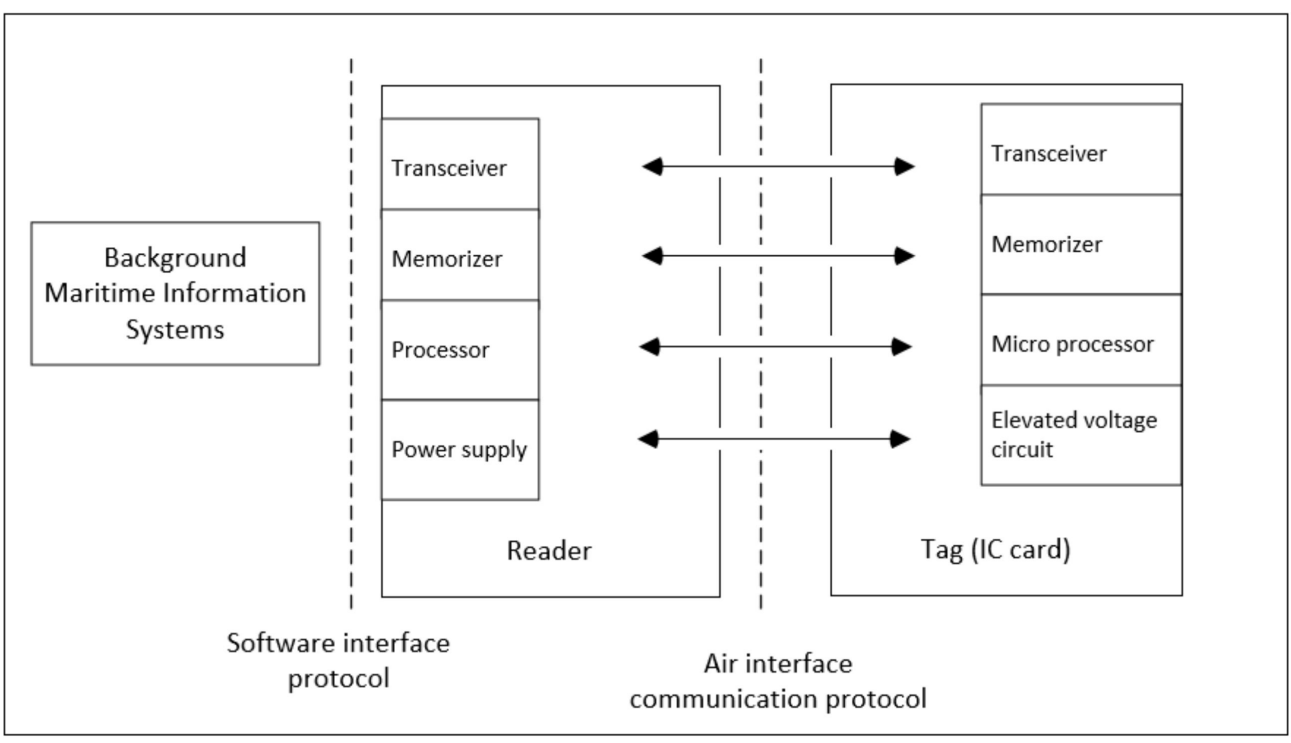

Figure 6. Working principle of a RFID system—based on the Reference [13].

Communication between the tag and RFID reader is one-sided. The tag informs the reader about its unique ID number which is then sent to middleware which is able to format and present data in the business application. There is a wide range of RFID technologies, nevertheless the most used are passive without batteries and active with batteries.

RFID is mainly used for the identification and tracking of people, assets and inventory distinguishing it from other AIDC technologies [19].

The main reasons to implement RFID technology are related to operational control as it provides asset visibility and performing process automation. It stays on the guard of safety by ensuring the protection of workers and equipment and security by assuring access control, securing assets and inventory.

The longer read distance and the large number of assets which RFID is able to identify and locate at the same time are the greatest advantages of this technology. An RFID tag on a container or truck can be read from almost a kilometer in some cases. On the other hand, the above advantages in some cases can be treated as disadvantages-especially when high accuracy of asset location is needed [13].

\subsection{Selection of AIDC Technology for the DCT Gdańsk SA}

Deepwater Container Terminal in Gdańsk, after the evaluation of serval different AIDC technologies as presented in Table 2, decided to implement gate automation into its gate complex and called the project: gate optimization process. The project was appointed in 2017 and implemented in 2019. DCT Gdańsk SA road gate complex rebuilding was planned and included in the container terminal program development. The main project goal was to have gate operation processes (GOP) supported by relevant infrastructure and IT systems that enables us to safely handle declared (in a business plan) containers throughput via the gate complex. In other words, GOP shall not be a bottleneck for container flow but shall work as a facilitator. The potential cap (in the future) shall be caused by limits of the infrastructure itself, not the gate processes. During the program initiation phase, all AICD 
technologies were investigated. DCT decided to use OCR technology as the one which implementations and introduction responsibility will be fully on the terminal side. The main reason for not considering and selecting RFID technology was the additional cost of RFID tags for terminal clients. A huge number of trucks and trailers will need to be tagged, not to mention about containers-additional costs and manual process of every tag programming and typing in the system-would not be received positively.

Table 2. Comparison of automated identification and data collection technologies—based on references [12,13,19].

\begin{tabular}{|c|c|c|}
\hline AIDC Technologies & Main Advantages & Main Disadvantages \\
\hline Barcode & Low costs & $\begin{array}{l}\text { Easy worn-out } \\
\text { Limited data storage } \\
\text { Invalid in darknes }\end{array}$ \\
\hline Contact ID card & $\begin{array}{l}\text { Better data storage } \\
\text { Better data security }\end{array}$ & $\begin{array}{c}\text { Easy worn-out } \\
\text { Easy to lose } \\
\text { Easy to steal and impersonate }\end{array}$ \\
\hline OCR & $\begin{array}{l}\text { High volume of events } \\
\text { High efficency and accuracy } \\
\text { Possible claim management }\end{array}$ & $\begin{array}{l}\text { High costs in system and infrastructure } \\
\text { System need to be maintained }\end{array}$ \\
\hline Magcard & Low costs & $\begin{array}{c}\text { Easy worn-out } \\
\text { Limited data storage } \\
\text { Magnetism need to be maintained }\end{array}$ \\
\hline RFID & $\begin{array}{c}\text { Low requirement for working environment } \\
\text { High accuracy and efficiency }\end{array}$ & $\begin{array}{c}\text { High costs } \\
\text { TAGs given to 3rd party users } \\
\text { Easy to cover or damage }\end{array}$ \\
\hline
\end{tabular}

Introducing OCR, optical character recognition and contact ID cards for truck drives as a part of automated gate strategy significantly increased gate throughput through automatic capture and processing of truck and container data. Issues or exceptions are handled by a decreased number of staff working in the office, instead of being exposed to harsh and risky outdoor conditions. Automation and accuracy improved truck turnaround times.

The gate optimization process uses automatic gate systems which help to establish a connection at gate terminals between trucks and trains with terminal operators. Trucks handling at the terminal gates are controlled by the gate operating system (GOS). To process the collected data, communication was established between the customer's advanced gate operating system and the terminal's terminal operating system (TOS). The gate optimization system uses camera portals and optical recognition to read the number on the container, ISO codes, truck and trailer license plates and verifies seal presence plus IMDG labels status.

With the new auto gate system, gate transactions are easier, faster, and more secure, drivers can remain inside their vehicles during inspection, security checks and container movements.

The new gate automation system uses a combination of smart card technology, optical character recognition (OCR) cameras and unmanned driver kiosks to allow registered drivers to go through the terminal's gates with no documentation flow or delays.

Road gates equipped with OCR camera portals, which process container data and capture images for condition recording. The terminal's road gate lanes equipped with a driver kiosk, which will validate all data and present drop and pick-up zones.

This project significantly reduces the global costs of gate operations and leads to higher operating safety and efficiency, better productivity and profitability. 


\section{Results and Discussion}

The main requested functionality of automated road gates which utilizes the OCR technology is to cope with high truck volumes during peak hours. The simulation includes an analysis of three main factors related to the final gate layout:

- Waiting time to in-gates and out-gates;

- Road truck queues at in-gates and out-gates;

- Number of road trucks in terminal.

Main simulation outputs were determined based on the entered input data into the simulation model.

Input data which was taken into consideration were related to cargo types, road truck handling times, automated gate accuracy and processing times.

\subsection{Evaluation of the Automated Gate Layout}

Evaluation was performed based on the summer peak day on 30 June 2017 (Friday) with a total of 2047 trucks visiting the terminal in $24 \mathrm{~h}$, with hourly variation-Table 3 . Peak hours were between 12:00-17:00 and 18:00-01:00 with extra high peak at 18:00-19:00. The day of 30 June 2017 was chosen to perform evaluation as the day after completion of all discharge containers operations from the mainliner vessel call and one day before the weekend summer truck stoppage (during summer weekends trucks are not allowed to transport containers).

Table 3. Road container traffic—summer peak day—DCT Gdańsk SA.

\begin{tabular}{ccc}
\hline \multirow{2}{*}{ Traffic/Road Containers } & \multicolumn{2}{c}{ Peak Day with 2047 Truck Visits } \\
\cline { 2 - 3 } & In-Gate & Out-Gate \\
\hline With $20 \mathrm{ft}$ container & $20 \%$ & $26 \%$ \\
\hline With $40 \mathrm{ft}$ container & $37 \%$ & $40 \%$ \\
\hline With empty chassis & $41 \%$ & $32 \%$ \\
\hline Total road truck with container & $98 \%$ & $98 \%$ \\
\hline Total container & $46 \%$ & $54 \%$ \\
\hline
\end{tabular}

The main challenge related to implementation the OCR technology is related with the gate complex layout which is direct connected to the whole infrastructure costs. The number of truck lanes in the self-service, security gate in and security gate out is crucial to estimate and properly evaluate. OCR portals (damage inspection portals) are installed before enter and exit to/from the terminal, for recognition of truck, trailer and container purpose. As they are driven through infrastructure points-for the purpose of their reliability and security of terminal interests-it is always worth installing more than one portal in the enter and exit areas.

DCT Gdańsk SA evaluated the automated gate layout based on the below presented comparisons:

In-gate:

- $\quad 4$ or $5 \times$ self-service lanes with a driver kiosk and LPR (results in Figure 7);

- 3 or 4 or $5 \times$ security gate lanes with a driver kiosk and LPR (results in Figure 8);

- out-gate:

- 3 or 4 or $5 \times$ security gate lanes with a driver kiosk and LPR (results in Figure 9);

DCT Gdańsk SA evaluated the automated gate layout based on the below presented assumptions:

- OCR/LPR accuracy at in- and out-gate:

$>$ for containers: $98 \%$

$>$ for license plates: $97 \%$ 
- $\quad$ OCR/LPR correction time:

$>\quad$ average: $75 \mathrm{~s}$
$>\quad$ minimum: $30 \mathrm{~s}$
$>\quad$ maximum: $120 \mathrm{~s}$

- Automated Gate processing times:

> Self-service lanes: Minimum: 30 s, maximum 90 s, average $60 \mathrm{~s}$

$>\quad$ Security IN gates: Minimum: $20 \mathrm{~s}$, maximum $60 \mathrm{~s}$, average $40 \mathrm{~s}$

> Security OUT gates: Minimum: 15 s, maximum 35 s, average $25 \mathrm{~s}$

\subsection{Simulation Results of the Automated Gate Layout}

Simulation results presented in Figures 7-9 take into account the time stamps when the road truck leaves (starts to drive from) the kiosk in the gate lane. Queue size shows the number of road trucks before the road truck in the chosen lane, when arriving to the kiosk in self-service and/or gate. For the purpose of the simulations, we have assumed that the road truck always chooses the lane with the shortest queue (free lane selection).

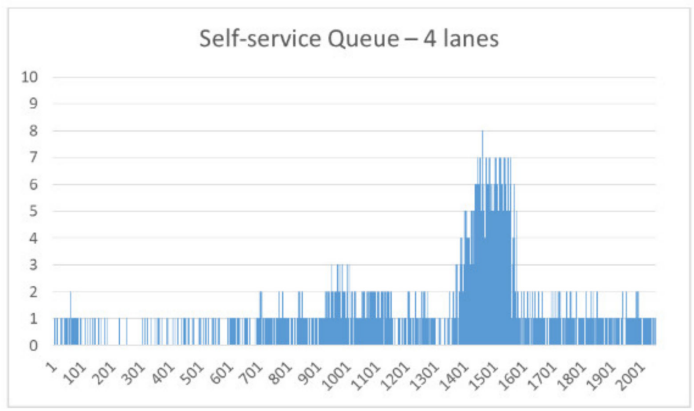

(a)

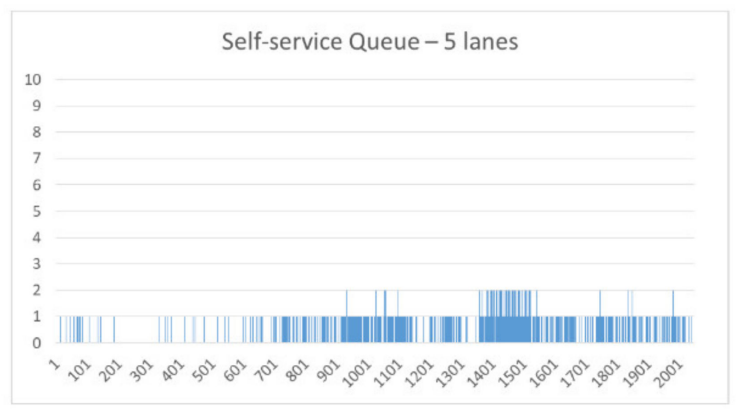

(b)

Figure 7. Self-service queue-4 (a) vs. 5 (b) lanes comparison.

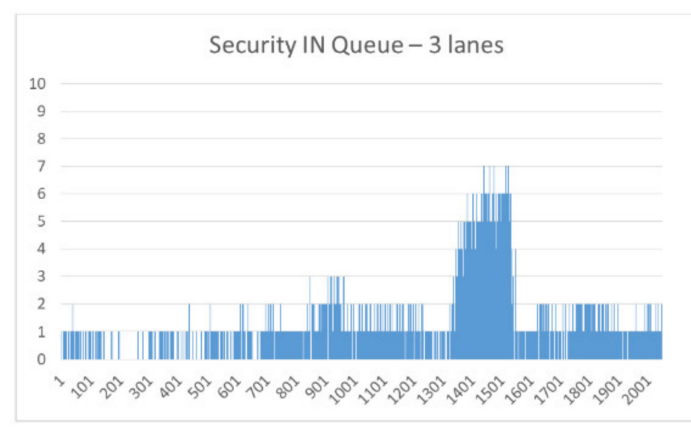

(a)

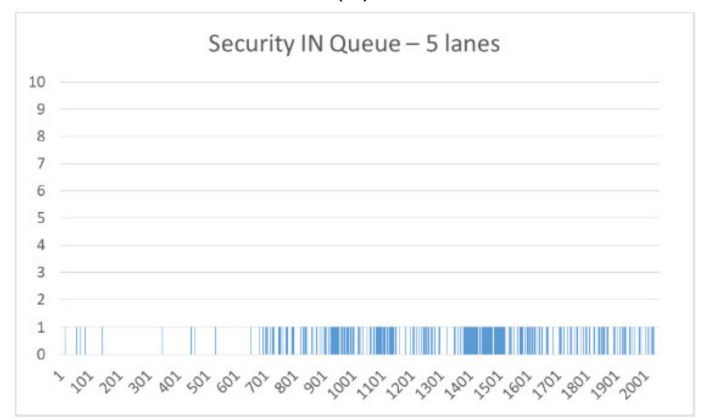

(c)

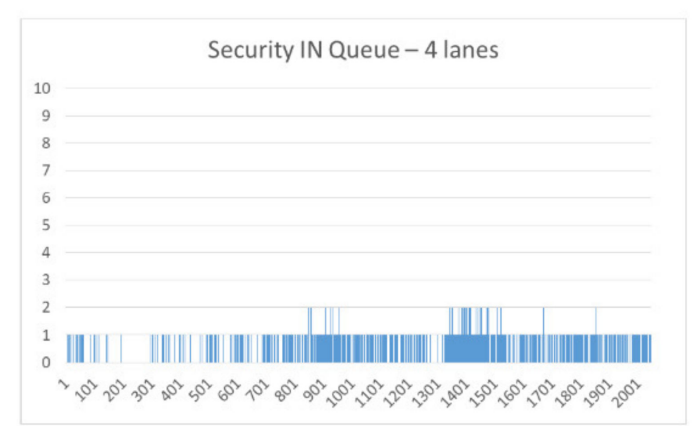

(b)

Figure 8. Security IN queue-3 (a) vs. 4 (b) vs. 5 (c) lanes comparison. 
It is clearly seen that the queues to gate complex points self-service (Figure 7), security IN (Figure 8 ) and security OUT (Figure 9) are minimal when five lanes are utilized:

- Self-service lanes-various scenarios show that 5 lanes are giving a significant reduction in waiting time-max queue 8 trucks with 4 lanes, and queue only up to 2 trucks with 5 lanes;

- Security IN lanes-4 lanes is optimal (3 lanes gives a max queue of 7 trucks, 4 or 5 lanes similar short queues);

- Security OUT lanes-verified processing time shows that OUT process is significantly shorter than IN process. Here 3 or 4 lanes OUT would suffice (max queue 2 or 3 trucks respectively).

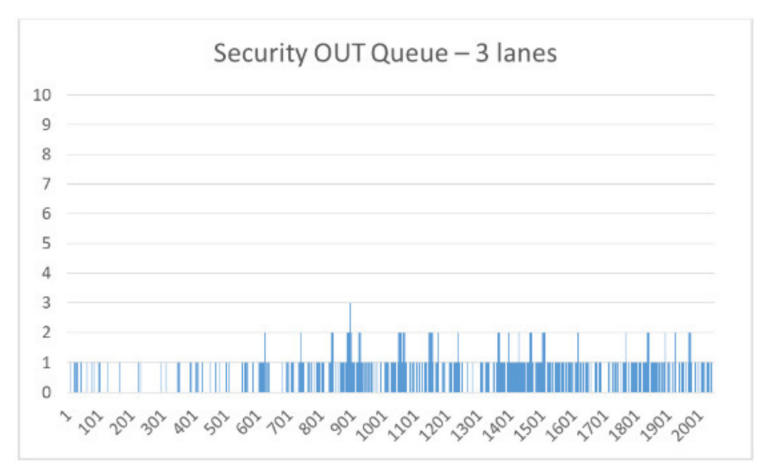

(a)

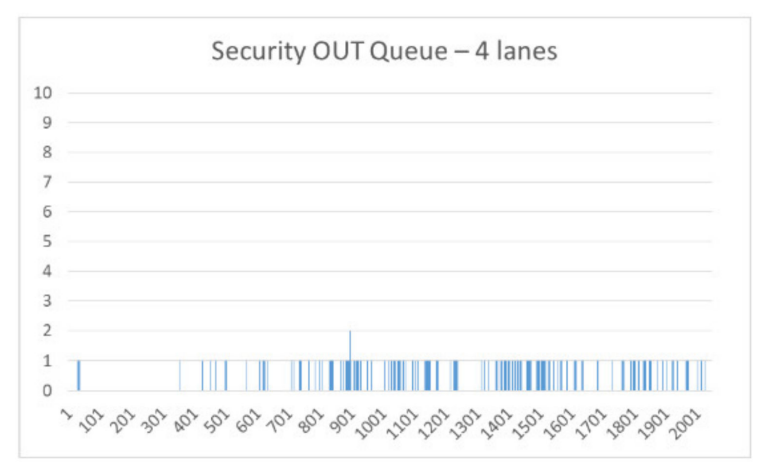

(b)

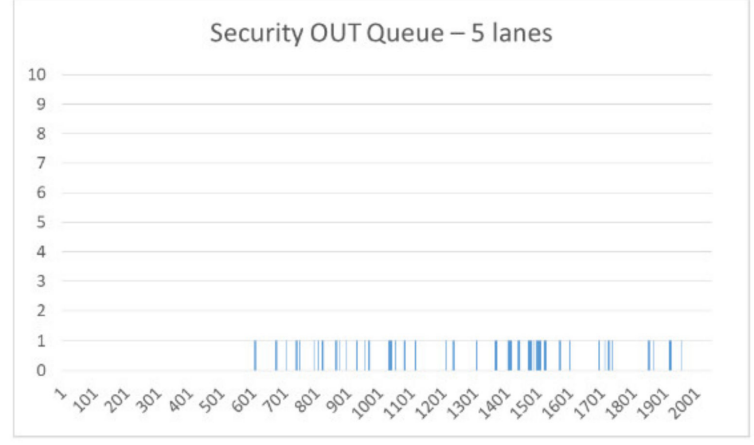

(c)

Figure 9. Security OUT queue-3 (a) vs. 4 (b) vs. 5 (c) lanes comparison.

Results presented in Figures 7-9 were the crucial information about the future automated gate layout. Only when the simulations were performed and discussed, DCT Gdańsk was able to decide about building an adequate terminal gate complex infrastructure which was part of the big development program.

\subsection{OCR Processing and Accuarty Rate}

The accuracy rate for the gate automation process is having a crucial meaning when the processing times are respectively considered, since the correction effects affect the automated process. The emergence of exceptions-incorrect OCR readings-in most cases causes the need for manual operator work which takes additional processing time to find a proper event-and to verify it and correct it. Table 4 presents the assumed vs. current status of gate automation process conditions. 
Table 4. Assumed vs. Current OCR Processing and Accuracy rates.

\begin{tabular}{|c|c|c|c|c|}
\hline & \multicolumn{2}{|c|}{ Assumed } & \multicolumn{2}{|c|}{ Current } \\
\hline & Processing times & Accuracy rate & Processing times & Accuracy rate \\
\hline OCR IN portals & Drive-through & $\begin{array}{l}>95 \% \\
\text { container/registration }\end{array}$ & Drive-through & $>98 \%$ container / registration \\
\hline Self-service lanes & 30-90 sec.: 60 sec. average & $>97 \%$ registration & 20-60 sec: 40 sec. average & $>99 \%$ registration \\
\hline Security In lanes & 20-60 sec.: 40 sec. average & $>97 \%$ registration & 15-40 sec: 30 sec. average & $>99 \%$ registration \\
\hline OCR OUT portals & Drive-through & $\begin{array}{l}>95 \% \\
\text { container/registration }\end{array}$ & Drive-through & $>98 \%$ container $/$ registration \\
\hline Security Out lanes & $\begin{array}{l}\text { 15-35 sec.: } 22.5 \mathrm{sec} \\
\text { average }\end{array}$ & $>97 \%$ registration & 10-25 sec: 15 sec. average & $>99 \%$ registration \\
\hline
\end{tabular}

As can be seen in Table 4-the current accuracy rate is higher than assumed. This shows how reliable and accurate the OCR system is. Nevertheless, it is important to think about these small percentage of manual exceptions which in total, when the terminal handles over 2000 trucks daily, can exceed 100 exceptions per day. To speed up the time for the manual work correction process, it is crucial to consider supporting system implementation. Such system can be closed-circuit television or better known as CCTV which can be seen in self-service lines in Figure 10. The supporting system and a direct view on the current situation in every stage of the gate process can strengthen the possibility of fast solution to the exceptions which occur. Manual intervention and direct support of the driver which is blocking the line with his truck will give significant results when the supporting system is applied.

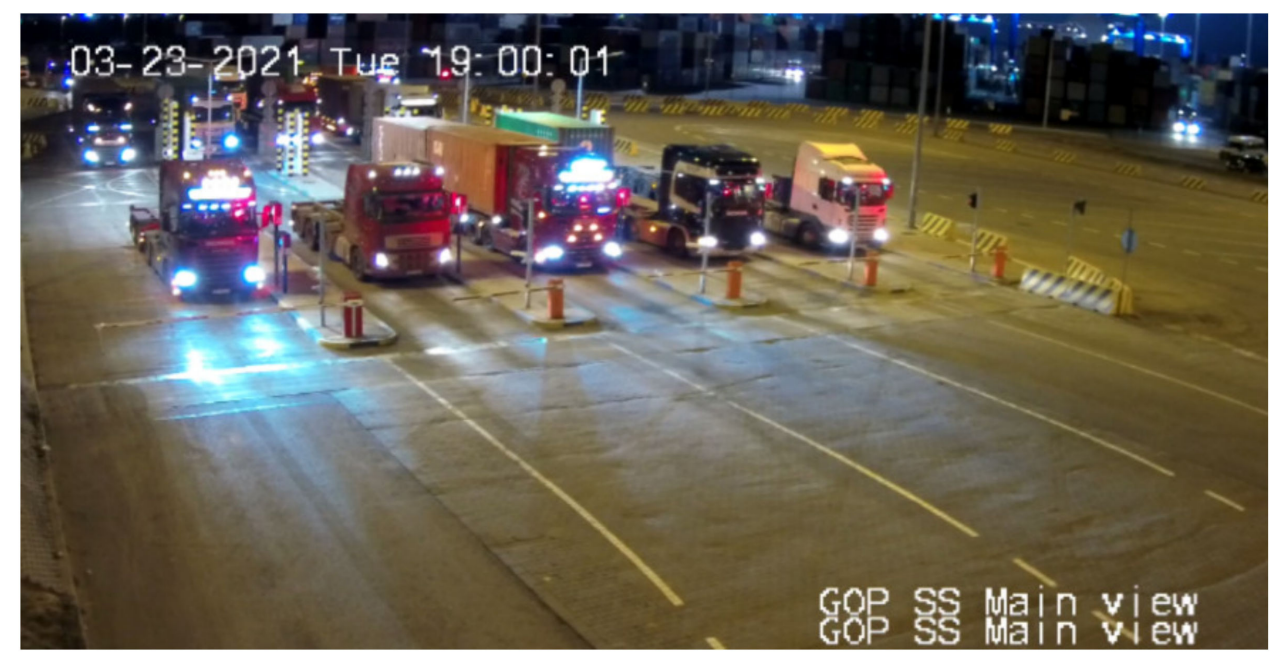

Figure 10. CCTV view on the self-service lanes at the DCT Gdańsk SA.

\subsection{The Final Automated Gate Layout}

Taking all the above analyses and simulation results into consideration, the automated gate layout was built. Gate complex includes OCR portals with OOG line $(2 \times$ IN and $2 \times$ OUT) as presented in Figure 11 and self-service $5 \times$ lanes, security in $5 \times$ lanes in and out $5 \times$ lanes as shown in Figure 12. Automated gate operation process implementation allowed us to automatize the handling of trucks at container terminal gates by using OCR (optical camera recognition), LPR (license plate recognition) technology and self-service kiosks for truck drivers. 


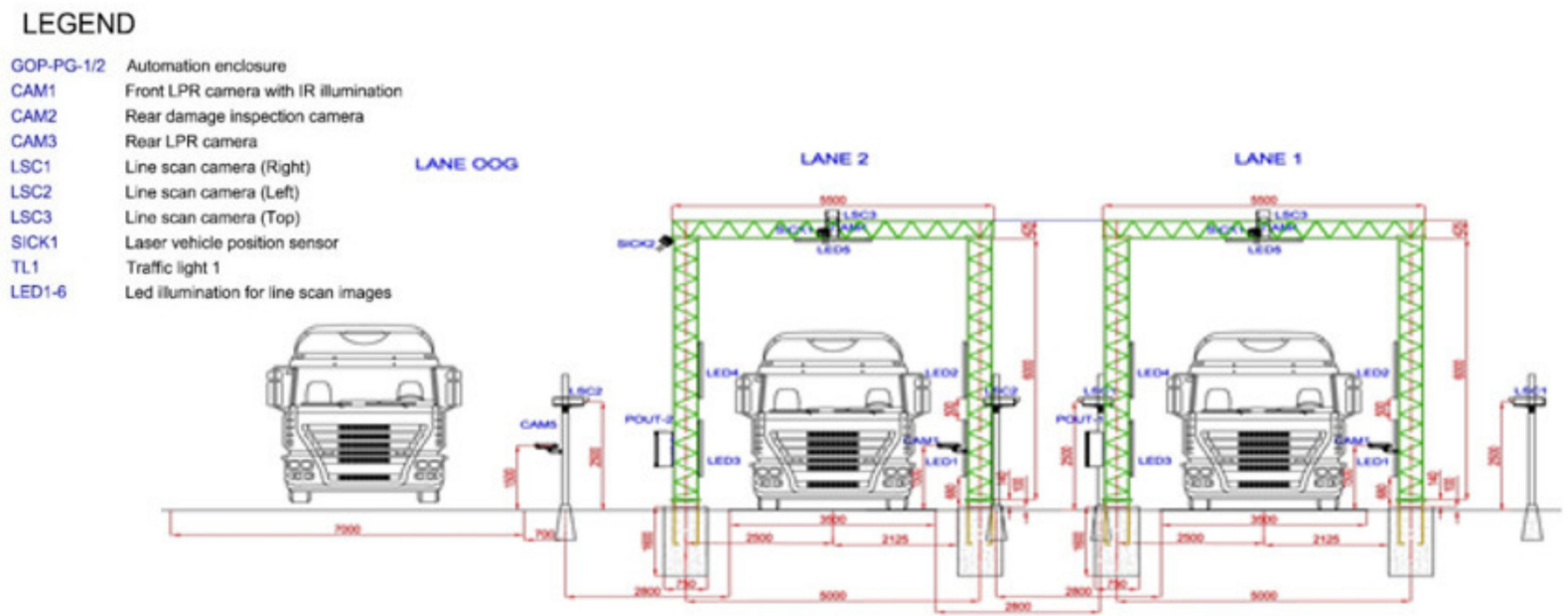

Figure 11. OCR In and OUT portals with OOG line.

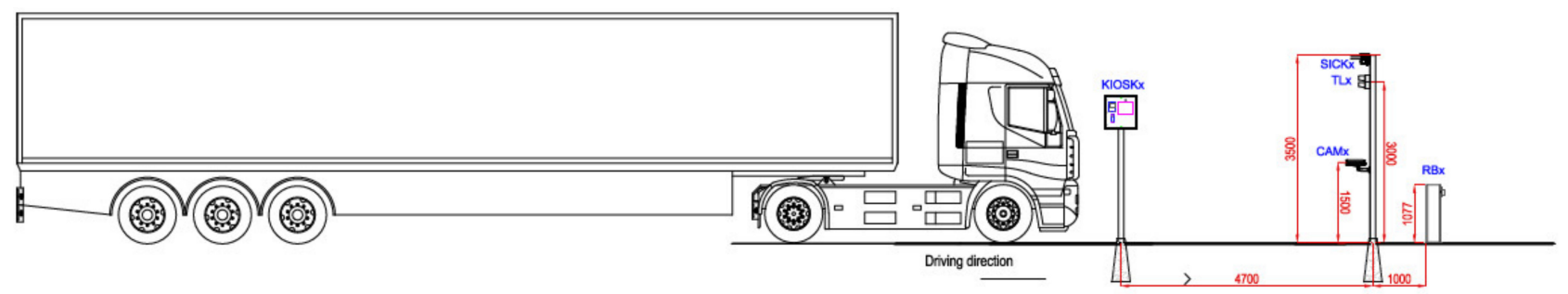

LANE 5

LANE 4

LANE 3

LANE 2

LANE 1

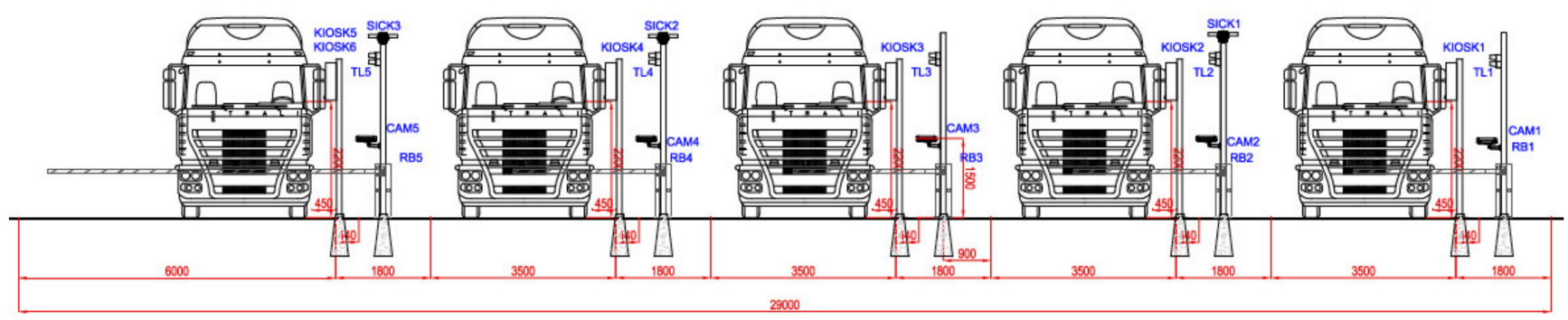

\section{LEGEND}

KIOSKX Self-service kiosk

CAMx Front LPR camera

SICKX Laser cart position sensor

RBX Road barrie

TLX Traffic light

Figure 12. Self-service kiosks, security IN and OUT lanes.

Road imaging OCR Portals and OOG bypass line as presented in Figure 11 are installed before entering and leaving DCT Gdańsk SA and are divided into functional zones using concrete fencing. Areas operate as drive-through lanes without stopping. Portals imagine and recognize truck and container data. Pictures are stored in the database for an appropriate time, later when the needed pictures can be exported to an external archive. On both areas the system will take pictures of: LPR cameras-truck registration, line scan cameras-container (two sides and roof), rear damage inspection camera-container doors.

The system identifies container ID, ISO code-identification of container type and size, IMO code and ADR labels, high security seal (bottle) presence, container position, 
door direction, and chassis TEU. Empty trucks are also required to drive through OCR portals for registration number detection.

Self-service area and Security IN and OUT areas as presented in Figure 12 are dedicated for the driver self-service process. The driver identifies himself and enters/checks/confirms all visit details, TOS (terminal operating system) will validate the visit based on the submitted data. Driver self-service kiosks are multilingual (four languages: Polish, English, Russian, and Ukrainian).

The front truck LPR cameras identify truck in the lane. Further information is displayed to the driver in a driver self-service kiosk. There are built five lanes, where five are dedicated for container traffic and one of them for CFS, OOG and other traffic.

The self-service area and security IN and OUT area contain all necessary equipment to handle automation such as: truck front LPR cameras, driver self-service kiosks with $15^{\prime \prime}$ touch screens, intercom, driver ID card reader and driver face camera, and laser scanners for truck detection.

The system verifies truck visit appointment details with TOS. Exception handling-all information given on a self-service kiosk. Information about the next steps/instructions is given on the kiosk screen and sent by SMS to driver's phone.

\subsection{Discussion}

To handle increasing amounts of container traffic, many terminal operators have applied OCR systems to improve the operational efficiency of their gates. These days, additional terminal subsystems such as gate operating systems (GOS) have become a necessity due to the operational requirements to reduce costs (both labor and equipment) and increase throughput.

When OCR technology is implemented, the human-machine interaction is minimized. There are no people working outside the gates during standard operations. A truck driver during the whole process does not meet no one at the gates-he is able to enter the terminal without any face to face "conversation". Gate automation gives huge benefits when considering coronavirus disease (the COVID19 pandemic).

With the implementation of OCR technology and utilizing two OCR IN and two OCR OUT portals there is the ability to handle more than 200 trucks per hour. In Q1 2020 DCTG were handling over 150 trucks per hour without any issues.

OCR technology has its own limitations and the main one is related to the number of trucks which it is able to handle during a single hour. Whenever the container terminal plans to increase its handling capacity and develop new berths or purchase new ship-toshore container cranes, it is crucial to always investigate and simulate the container growth impact on the automated gates.

One of the major values of the OCR implementation is the network asset visibility and increased asset utilization by providing the critical core information to execute advanced decision making on the movement of containers and other transport assets, enabling improved supply chain process management and thereby saving time and/or money.

Secondly, the key benefits of the operational control based on automated gates are related to increased productivity and data accuracy, improved efficiency, and utilization. Increase of gates throughput without additional investment in the infrastructure is always considered as the highest advantage of automated solutions.

Implementing OCR technology significantly reduces the global costs of gate operations and leads to higher operating safety and efficiency, better productivity and profitability by:

- freed valuable resources;

- the higher container throughput going IN and OUT of the gates;

- gate transactions are easier, faster and more secure;

- no documentation flow or delays;

- validation of all data.

Finally, the biggest priority and the highest advantages of automated gates are measured through safety and security. By applying OCR solutions terminal operators increase 
visibility, facility and asset security. Automated systems separate man and machine interaction and positively influence on the whole cargo flow.

\section{Conclusions}

The authors proposed the research methodology which can be applied by any of the container terminal operators for the selection of the automated gate layout with required equipment. It is essential during the analyzing process of the automated identification and data collection (AIDC) technology to follow described by the authors selection methodology which was successfully implemented in the Deepwater Container Terminal Gdańsk SA.

The current situation at DCT Gdańsk gate complex has been substantially improved. All trucks are handled via an automated gate and the container's flow runs smoothly without any disturbances. The objectives and goals of the automated gate implementation have been achieved.

Nevertheless, there is always room for improvement, so in the next stage of additional research, we will focus on the introduction of RFID technology with its integration within existing automated gates. We are planning to perform evaluations, simulations and tests of the above described arrangement to investigate if such a setup will bring us closer to the accuracy level above $99 \%$.

Author Contributions: Conceptualization, K.M. and M.D. (Mariusz Deja); methodology, K.M., M.D. (Mariusz Deja) and M.D. (Michal Dobrzynski); formal analysis, K.M. and M.D. (Mariusz Deja); resources, K.M.; data curation, K.M.; writing—original draft preparation, K.M. and M.D. (Mariusz Deja); writing—review and editing, K.M., M.D. (Mariusz Deja) and M.D. (Michal Dobrzynski); visualization, K.M.; supervision, M.D. (Mariusz Deja); project administration, K.M.; funding acquisition, K.M., M.D. (Mariusz Deja) and M.D. (Michal Dobrzynski). All authors have read and agreed to the published version of the manuscript.

Funding: Research was partially financed by Polish budget funds for science from Ministerstwo Edukacji i Nauki as a research project 0059/DW/2018/DW/2018/02.

Institutional Review Board Statement: Not applicable.

Informed Consent Statement: Not applicable.

Data Availability Statement: Data sharing not applicable to this article.

Conflicts of Interest: The authors declare no conflict of interest.

\section{References}

1. Guan, C.Q. Analysis of marine container terminal gate congestion, truck waiting cost, and system optimization. Ph.D. Thesis, New Jersey Institute of Technology, Newark, NJ, USA, 2009. Available online: https://digitalcommons.njit.edu/dissertations/902 (accessed on 1 February 2021).

2. Park, N.K.; Suh, S.C. Tendency toward mega containerships and the constraints of container terminals. J. Mar. Sci. Eng. 2019, 7, 131. [CrossRef]

3. Grubisic, N.; Krljan, T.; Maglic, L. The optimization process for seaside operations at medium-sized container terminals with a multi-quay layout. J. Mar. Sci. Eng. 2020, 8, 891. [CrossRef]

4. Deja, M.; Dobrzyński, M.; Siemiątkowski, M.S.; Wiśniewska, A. Simulation studies into quayside transport and storage yard operations in container terminals. Pol. Marit. Res. 2017, 24, 46-52. [CrossRef]

5. Wang, D. Dynamic optimization model of container route loading for international logistics ships. J. Coast. Res. 2019, 93, 1111-1116. [CrossRef]

6. Hur, S.H.; Lee, C.; Roh, H.S.; Park, S.; Choi, Y. Design and simulation of a new intermodal automated container transport system (ACTS) considering different operation scenarios of container terminals. J. Mar. Sci. Eng. 2020, 8, 233. [CrossRef]

7. Maguire, A.; Ivey, S.; Golias, M.M.; Lipinski, M.E. Relieving congestion at intermodal marine container terminals: Review of tactical/operational strategies. In Proceedings of the 51st Annual Transportation Research Forum 2010, Arlington, VA, USA, 11-13 March 2010. [CrossRef]

8. Porter, C.; Suhrbier, J.; Plumeau, P.; Campbell, E. Effective practices for congestion management: Final report. Prepared for the American Association of State Highway and Transportation Officials (AASHTO) and conducted as part of National Cooperative Highway Research Program (NCHRP) Project 20-24(63)_FR. 2008. Available online: http://onlinepubs.trb.org/onlinepubs / archive/NotesDocs/20-24(63)_FR.pdf (accessed on 1 February 2021). 
9. Fan, L.; Wilson, W.W.; Dahl, B. Congestion, port expansion and spatial competition for US container imports. Transp. Res. Part E Logist. Transp. Rev. 2012, 48, 1121-1136. [CrossRef]

10. Dekker, R.; van der Heide, S.; van Asperen, E.; Ypsilantis, P. A chassis exchange terminal to reduce truck congestion at container terminals. Flex. Serv. Manuf. J. 2013, 25, 528-542. [CrossRef]

11. Chao, S.L.; Lin, Y.L. Gate automation system evaluation: A case of a container number recognition system in port terminals Marit. Bus. Rev. 2017, 20, 21-35. [CrossRef]

12. OCR in Ports and Terminals, A PEMA Information Paper. Available online: https://www.pema.org/wp-content/uploads/ downloads / 2013/01/PEMA-IP4-OCR-in-Ports-and-Terminals.pdf (accessed on 1 February 2021).

13. Dehghani, H.; Kesbat, S.; Fereshtegan, M. RFID and OCR technology in ports and container terminal. In Proceedings of the 3rd International Conference 2016, Research in Science and Technology, Berlin, Germany, 9 July 2016. Available online: https: / / www.sid.ir/en/seminar/ViewPaper.aspx?id=26172 (accessed on 1 March 2021).

14. Karafa, J.P. Simulating Gate Strategies at Intermodal Marine Container Terminals. Ph.D. Thesis, University of Memphis, Memphis, TN, US, May 2012. Available online: https://www.memphis.edu/ifti/pdfs/student_reserach_jeff_karafa.pdf (accessed on 1 February 2021).

15. Cao, M.; Golias, M.M.; Karafa, J. Evaluation of the Effect of Gate Strategies in Drayage Related Emissions (No. CFIRE 04-19); National Center for Freight and Infrastructure Research and Education, Department of Civil and Environmental Engineering, University of Wisconsin-Madison: Madison, WI, USA, 2013. Available online: https://rosap.ntl.bts.gov/view/dot/26174 (accessed on 1 February 2021).

16. Grubisic, N.; Krljan, T.; Maglić, L.; Vilke, S. The microsimulation model for assessing the impact of inbound traffic flows for container terminals located near city centers. Sustainability 2020, 12, 9478. [CrossRef]

17. Xu, B.; Liu, X.; Yang, Y.; Li, J.; Postolache, O. Optimization for a multi-constraint truck appointment system considering morning and evening peak congestion. Sustainability 2021, 13, 1181. [CrossRef]

18. Qu, W.; Tao, T.; Xie, B.; Qi, Y. A state-dependent approximation method for estimating truck queue length at marine terminals. Sustainability 2021, 13, 2917. [CrossRef]

19. Dempsey, M. RFID in Ports and Terminals. Information Paper of the Port Equipment Manufacturers Association (PEMA). 2013. Available online: https:/ /www.pema.org/wp-content/uploads/downloads/2011/06/PEMA-IP1-RFID-in-Ports-and-Terminals. pdf (accessed on 1 February 2021). 